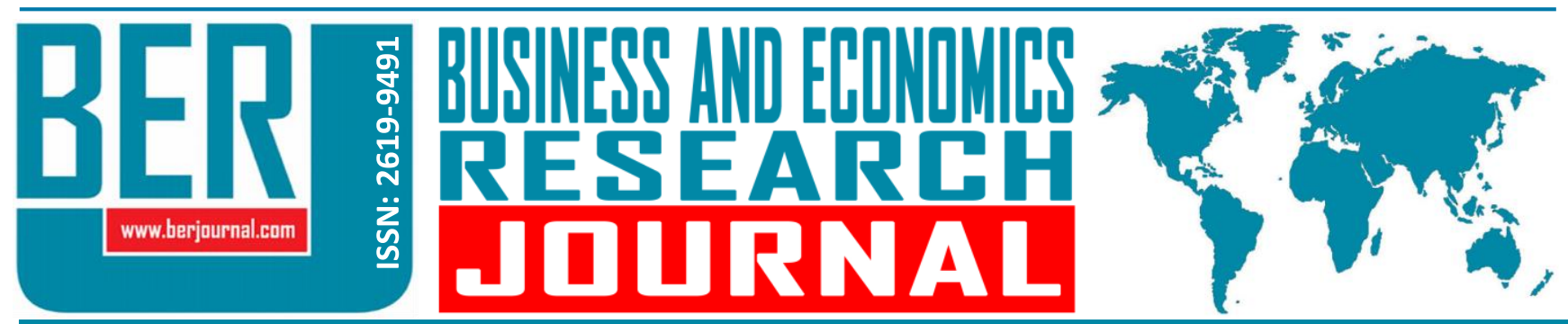

Business and Economics Research Journal Vol. 11, No. 4, 2020, pp. 989-1000 doi: 10.20409/berj.2020.294

\title{
Türkiye'de Hanehalkı ve Reel Sektör Beklentileri Arasındaki İlişkinin Analizi
}

\author{
Necmettin Alpay Kocak ${ }^{\mathrm{a}}$
}

Öz: Hanehalkı ve reel sektör beklentileri ile ekonomik göstergeler arasındaki ilişki literatürde sıkça tartısıılmaktadır. Bu çalışmada ise hanehalkı beklentileri ile reel sektör beklentileri arasındaki ilişkinin varlığı ve boyutları, Tüketici Güven Endeksi (TGE) ve Reel Kesim Güven Endeksi'nin (RKGE) alt endeksleri arasında araştırılmıştır. 2007 Ocak-2020 Nisan döneminin analiz edildiği çalışmada literatürden farklı olarak, ilişkinin varlığının ortaya konulmasında ve seviyesinin ölçülmesinde, zamana bağlı değişen (dinamik) koşullu korelasyonları tahmin eden DCC-GARCH yöntemi kullanılmıştır. Çalışmanın literatürden bir diğer farklıı̆ı, endeksler arasındaki ilişkilerde USD/TL kurunun ve COVID-19 salgınının etkilerini panel veri analizi ile ölçmeye çalışmasıdır. Elde edilen bulgular, TGE ve RKGE alt endeksleri arasında ilişkinin genel anlamda var olduğunu göstermektedir. Özellikle hanehalkının genel ekonomiye ve işsizliğe ilişkin beklentilerini gösteren TGE alt endeksleri ile reel kesimin ekonominin genel gidişatına ve sipariş miktarlarına ilişkin beklentilerini gösteren RKGE alt endeksleri arasında ilişkinin istatistiksel olarak anlamlı olduğu tespit edilmiştir. Panel veri analizi bulguları, USD/TL kurunun TGE ve RKGE alt endeksleri arasındaki ilişkiyi ters yönde etkilediğini, buna karşın COVID-19 salgının söz konusu ilişkiyi etkilemediğini işaret etmektedir.

\section{Analysis of the Relationship between Household and Real Sector Expectations in Turkey}

Abstract: The relationship between household and real sector expectations and economic indicators has been frequently discussed in the literature. On the contrary, the existence and dimensions of the relationship between household expectations and real sector expectations are investigated between the sub-indices of Consumer Confidence Index (CCI) and the Real Sector Confidence Index $(B C I)$ in this study. Unlike the literature, the DCC-GARCH method, which estimates time-varying (dynamic) conditional correlations, is used in this study for the period between January 2007-April 2020. Another difference of the study from the literature is that it tries to measure the effects of the USD/TL exchange rate and the COVID-19 outbreak on the dynamic relationship by panel data analysis. The findings revealed that the relationship between $\mathrm{CCl}$ and $\mathrm{BCl}$ sub-indices do exists in a general manner and there is a statistically significant relationship between the $\mathrm{CCl}$ sub-indices which represent the household expectations regarding the general economy and unemployment, and the $\mathrm{BCl}$ sub-indices which represent the real sector expectations regarding the general course of the economy and order amounts. The panel data analysis findings indicate that the USD/TL exchange rate adversely affects the relationship between $\mathrm{CCl}$ and $\mathrm{BCl}$ sub-indices, whereas the COVID-19 outbreak does not affect the relationship.

Anahtar Sözcükler: Tüketici Güven Endeksi, Reel Kesim Güven Endeksi, Dinamik Koşullu Korelasyon, Döviz Kuru, COVID-19

JEL: C32, C53, E31, E37

Geliş : : 01 Haziran 2020

Düzeltme : 28 Temmuz 2020

Kabul : : 11 Ağustos 2020

Tür : : Araştırma

Keywords: Consumer Confidence Index, Reel Sector Confidence Index, Dynamic Conditional Correlation, Exchange Rate, COVID-19

JEL: C32, C53, E31, E37

$\begin{array}{ll}\text { Received } & : 01 \text { June } 2020 \\ \text { Revised } & : 28 \text { July } 2020 \\ \text { Accepted } & : 11 \text { August } 2020\end{array}$

Type : Research 


\section{Giriş}

Ekonomik birimler, risk algıları ve beklentilerine göre kararlar almaktadırlar. Dolayısıyla, hanehalkları ve reel sektörün ekonomiye ilişkin görüş ve beklentilerinin izlenmesi politika yapıcılar açısından oldukça önemlidir. Beklentiler, hanehalkının tüketim-tasarruf tercihlerini ve reel sektörün yatırım risk algını yönlendirerek ekonomiyi etkileme gücüne sahiptir. Bunun yanında, hanehalkının tüketim-tasarruf tercihlerinin talep yoluyla reel sektörün üretimini ve dolayısıyla yatırım-risk algısını ya da reel sektörün üretiminin arz yoluyla hanehalkının tüketim-tasarruf tercilerini etkilemektedir.

Türkiye'de hanehalkları ve reel sektörün beklentilerini izlemek üzere başlıca iki endeks kullanılmaktadır. Bunlar, Türkiye İstatistik Kurumu tarafından hesaplanan Tüketici Güven Endeksi (TGE) ve Türkiye Cumhuriyet Merkez Bankası tarafından hesaplanan Reel Sektör Güven Endeksi (RKGE) göstergeleridir. TGE hem hanehalklarının güven seviyesini hem de alt endeksler aracılığıyla hanehalkının mali durumlarını, genel ekonomiye ilişkin mevcut durum değerlendirmeleri ile gelecek dönem beklentilerini ölçmektedir. RKGE ise hem reel sektörün ekonomiye güvenini hem de alt endeksler aracılığıyla sektörün üretim, istihdam, ihracat durumları ve beklentilerini ölçmektedir.

Literatürdeki çalışmalar kapsam ve yöntem açısından değerlendirildiğinde; TGE ve RKGE ile ekonomik göstergeleri arasındaki ilişkiler kısa ve uzun dönem bakış açısıyla nedensellik ve eş-bütünleşme testleri yardımıyla incelendiği görülmektedir. Ancak TGE ile RKGE arasındaki ilişkiyi analiz eden çalışmalar açısından literatürün zengin olmadığı göze çarpmaktadır.

Literatürden farklı olarak bu çalışmanın amacı TGE ve RKGE alt endeksleri arasındaki ilişkiyi analiz etmek ve bu ilişkinin zaman içindeki eğilimi üzerinde USD/TL ve COVID-19 salgınının etkilerini araştırmaktır. Bu çalışmada TGE ve RKGE'nin alt endeksleri arasındaki ilişkinin analizi 2007:01-2020:04 dönemi için DCCGARCH modeli kullanılarak zamana bağı değişen (dinamik) korelasyonlar yardımıyla araştırılmıştır. Sonrasında, Amerikan Dolar kurunun (USD/TL) ve COVID-19 salgınının TGE ve RKGE'nin alt endeksleri arasındaki ilişki üzerindeki etkileri panel veri analizi kullanılarak araştırılmışır.

TGE ve RKGE endeksleri hakkında çalışmalara ait literatür özeti ikinci bölümde sunulmuştur. Kullanılan veri ve yöntem, çalışmanın üçüncü bölümünde açıklanmıştır. Dördüncü bölümde ampirik bulgular sunulmuş, son bölümde ise çalışma ve bulgular değerlendirilmiştir.

\section{Literatür}

Reel sektör ve hanehalkı beklentileri ile ekonomik göstergeler arasındaki etkileşim merak edilen bir konu olduğundan, TGE ve RKGE'nin diğer ekonomik göstergeler ile ilişkileri literatürde sıklıkla incelenmiştir. Bir görüşe göre, TGE ve RKGE'nin hisse senedi getirileri gibi finansal göstergeler üzerinde anlamlı etkileri vardır (Bremmer ve Christ, 2003; Fisher ve Statman, 2003; Kandır, 2006; Korkmaz ve Çevik, 2009; Hsu, Lin ve Wu 2011; Chen, 2011; Ayuningtyas ve Koesrindartoto, 2014; Sum, 2014; Usul, Küçüksille ve Karaoğlan, 2017; Canöz, 2018). Bremmer ve Christ (2003) tarafından yapılan çalışmada, Dow Jones Sanayi, S\&P 500 ve NASDAQ hisse senedi bileşik endeksleri ile tüketici güven endeksi arasındaki ilişki 1984-2003 dönemi için açıklamaya çalışmışlardır. Eş-bütünleşme ve nedensellik analizleri sonucunda elde ettikleri bulgular, bileşik endeksler ile tüketici güven endeksi arasında uzun dönemli bir ilişkinin olmadığını ancak kısa dönemde bileşik endekslerin tüketici güvenini etkilediğini işaret etmektedir. Beklentiler ile finansal göstergeler arasındaki ilişkiyi destekleyen bir diğer çalışma ise Fisher ve Statman (2003) tarafından yapılan çalışmadır ve hisse senedi bileşik endeksi ile tüketici güven endeksi arasındaki ilişki 21 ülke ve 1999-2007 dönemi için panel Granger nedensellik testi yardımıyla analiz edilmiştir. Söz konusu çalışmada hisse senedi bileşik endeksi ile tüketici güven endeksi arasında çift yönlü nedensellik ilişkisi tespit edilmiştir. Son olarak, Kandır (2006) tarafından yapılan çalışmada ise tüketici güven endeksinin Borsa İstanbul'da işlem gören şirket hisse senedi getirilerini açıklayıp açıklamadığı test edilmiştir. 2002-2005 dönemi ve 28 şirket için yapılan regresyon modeli sonucunda, tüketici güven endeksinin 18 şirketin hisse senedi getirileri üzerinde pozitif etki yaptığı bulgusu elde edilmiştir. 
Literatürdeki bir diğer görüşe göre, TGE ve RKGE'nin üretim, tüketim ve fiyatlar gibi reel sektör göstergeleri üzerinde anlamlı etkisi vardır (Loría ve Brito, 2004; Arısoy ve Aytun, 2014; Islam ve Mumtaz, 2016; Yalçın, Tıraşoğlu ve Çevik, 2017; Albayrak, 2018; Ay, 2019; Demirgil, 2019; Yamak, Yamak ve Erkan, 2019). Loría ve Brito (2004) tarafından yapılan çalışmada Amerika'da özel sektörün yatırım ve tüketim harcamalarının tüketici güven endeksi kullanılarak tahmin edilebilirliğini araştırmışlardır. 1978-2003 dönemi için uygulanan eş-bütünleşme ve nedensellik testleri sonucunda kısa ve uzun dönemde tüketici güven endeksinden tüketim ve yatırım harcamalarına doğru anlamlı bir ilişki olmadığını göstermişlerdir. Islam ve Mumtaz (2016) ise tüketici güven endeksi ile ekonomik büyüme arasındaki ilişkiyi analiz etmişlerdir. Çalışmada, seçilmiş Avrupa ülkeleri ve 1996-2012 dönemi için yapılan panel eş-bütünleşme analizinin bulguları tüketici güven endeksi ve ekonomik büyüme arasında uzun dönemli ilişki bulunduğunu işaret etmektedir. Arisoy ve Aytun (2014) yürüttükleri çalışmada Türkiye'de tüketici güven endeksi ile tüketim harcamaları ve krediler arasındaki ilişki analiz edilmiştir. 2005-2012 dönemi için yapılan nedensellik testi sonucunda tüketici güven endeksinin diğer göstergeler ile pozitif yönde ilişkili olduğu ortaya konmuştur. Yalçın, Tıraşoğlu ve Çevik (2017) yürüttükleri çalışmada ise Türkiye'de tüketici güven endeksi ile konut fiyatları arasındaki ilişki bölgesel bazda incelenmiştir. 2010-2017 dönemi için yapılan eş-bütünleşme ve nedensellik testleri sonucunda bazı bölgelerde kısa ve uzun dönemde ilişkinin mevcut olduğu ve bu ilişkinin negatif olduğu görülmüştür. Albayrak (2018) ve Ay (2019) çalışmalarında ise sırasıyla 2007-2017 ve 2007-2019 dönemlerinde reel kesim güven endeksi ve imalat sanayi kapasite kullanım oranı arasındaki ilişki analiz edilmiştir. Ay (2019) yürüttüğü çalışmada kısa ve uzun dönemde iki yönlü ilişkinin varlığına işaret edilirken, Albayrak (2018) tarafından yapılan çalışmada ise uzun dönemde beraber hareket ve kısa dönemde reel kesim güven endeksinden kapasite kullanım oranına doğru tek yönlü nedensellik ilişkisi olduğu tespit edilmiştir. Yamak, Yamak ve Erkan (2019) yürüttükleri çalışmaya göre tüketici güven endeksi, 2004-2018 dönemi için Türkiye'de tüketim fonksiyonunda yer alması gereken bir değişkendir. Yazarların ARDL sınır testiyle elde ettikleri bulgular, tüketici güven endeksinin tüketimi uzun dönemde pozitif ancak zayıf bir şekilde etkilediğine işaret etmektedir.

Literatürde hem finansal hem de reel sektör göstergeleri ile TGE ve RKGE'yi ilişkilendiren çalışmalar da mevcuttur (Afshar, Arabian ve Zomorrodian, 2007; Beşel ve Yardımcıoğlu, 2016; Durgun, 2019). Afshar, Arabian ve Zomorrodian (2007) yürüttükleri çalışmada Amerika için tüketici, reel kesim ve yatırım güven endeksi ile gayri safi yurtiçi hasılanın dalgalanmaları arasındaki ilişki analiz edilmiştir. 1980-2005 dönemi için uygulanan VAR ve hata düzeltme modeli sonucunda güven endekslerinin gayri safi yurtiçi hasılayı açıklamada önemli rol oynadıkları sonucuna varılmıştır. Beşel ve Yardımcıoğlu (2016) yürüttükleri çalışmada Türkiye'de işsizlik, dolar kuru, petrol fiyatları ve tüketici güven endeksi arasındaki ilişkiler analiz edilmiştir. 2005-2014 dönemi için yapılan eş-bütünleşme ve nedensellik analizi sonucunda, döviz kurundan tüketici güven endeksine doğru bir nedenselliğin var olduğu tespit edilmiştir. Durgun (2019) yürüttüğü çalışmada Türkiye'de tüketici güven endeksi ve reel kesim güven endeksinin diğer ekonomik değişkenler ile ilişkileri araştırılmıştır. 2010-2018 dönemi için tahmin edilen VAR modellerinden elde edilen bulgular, tüketici güven endeksi ile enflasyon, döviz kuru ve BIST-100 endeksi arasında, diğer taraftan reel kesim güven endeksi ile üretim, faiz ve istihdam arasında karşılıklı etkileşim olduğuna işaret etmektedir.

Literatürdeki çalışmalar genel olarak değerlendirildiğinde hem tüketici güven endeksi hem de reel kesim güven endeksinin finansal ve reel göstergeler üzerindeki etkileşim içinde oldukları sonucuna varılmaktadır. Diğer taraftan, bu etkileşimin tek ya da çift yönlü olduğuna dair fikir birliği bulunmamaktadır. Tüketici güven endeksi ve reel kesim güven endeksi arasındaki ilişkinin doğrudan ve alt endeksler ayrımında analiz edilmemesi literatürde görülen eksiklik olarak göze çarpmaktadır. Sadece Gülcan ve Akkuş (2019) yürüttükleri çalışmada TGE ve RKGE arasındaki ilişki analiz edilmiştir. Yazarların 2007-2018 dönemi için eşbütünleşme ve nedensellik testleri yardımıyla elde ettiği bulgular çerçevesinde iki endeks arasında uzun dönemli bir ilişkinin var olduğunu ve TGE'den RKGE'ye doğru tek yönlü bir nedensellik olduğunu öne sürmüşlerdir. 


\section{Veri ve Yöntem}

Çalışmada Türkiye'ye ait TGE ve dört alt endeks ile RKGE ve sekiz alt endeks analiz edilmiştir. Kullanılan endeksler aşağıda verilmiştir.

- Reel kesim güven endeksi (RKGE)

- Reel kesim mevcut siparişler (RKMSIP)

- Reel kesim mevcut nihai mal stokları (RKMSTOK)

- Reel kesim gelecek 3 ay üretim hacmi beklentisi (RKG3UHCM)

- Reel kesim gelecek 3 ay istihdam beklentisi (RKG3IST)

- Reel kesim son 3 ay siparişleri (RKS3SIP)

- Reel kesim gelecek 3 ay ihracat siparişi beklentisi (RKG3IHRSIP)

- Reel kesim sabit sermaye yatırımı harcaması (RKYTHRCM)

- Reel kesim genel gidişat eğilimi (RKGG)

- Hanehalkı tüketici güven endeksi (TGE)

- Hanehalkı gelecek 12 ay maddi durum beklentisi (HG12MDB)

- Hanehalkı gelecek 12 ay genel ekonomik durum beklentisi (HG12GEDB)

- Hanehalkı gelecek 12 ay işsiz sayısı beklentisi (HG12ISSIZ)

- Hanehalkı gelecek 12 ay tasarruf etme intimali (HG12TSRRF)

Parantez içinde verilen kodlar, endeksleri temsil etmek üzere çalışmada kullanılmıştır. Mevsimsel düzeltilmiş ve skor değerleriyle temsil edilen endeksler için analiz dönemi olarak 2007:01-2020:04 aralığı belirlenmiştir. Skor değerleri, 0 ile 200 değerleri arasındaki endekslerinden 100 çıkarılarak elde edilmiştir. Böylelikle skor değerleri -100 ile 100 arasında değerler almaktadır. Veri, Türkiye i̇statistik Kurumu'nun Ekonomik Güven Endeksi veri tabanından mevsimsel düzeltilmiş olarak alınmıştır. Tablo 1'de çalışmada kullanılan veriye ilişkin tanımlayıcı istatistikler verilmiştir.

Bu çalışmada zamana bağlı değişen (dinamik) korelasyon katsayıları ile TGE ve RKGE alt endeksleri arasındaki ilişki, bir diğer ifadeyle TGE ve RKGE alt endekslerindeki şokların ortak hareketi DCC-GARCH modeli ile ölçülmeye çalışılmıştır. DCC (Dinamik Koşullu Korelasyon)-GARCH (Genelleştirilmiş Otoregresif Koşullu Regresyon) modeli yardımıyla tahmin edilen istatistiksel olarak anlamlı dinamik korelasyon katsayıları, her ne kadar TGE ve alt endekslerindeki şoklardan RKGE ve alt endekslerindeki şoklara doğru veya tersi yönde bir nedenselliği ifade etmese de iki şok arasında senkronizasyonun (ilişkinin) varlığını işaret etmektedir.

DCC modelinin tahmini iki aşamadan oluşmaktadır. Öncelikle her bir değişken için bir GARCH modeli tahmin edilir ve bu aşamadan elde edilen standartlaştırılmış hata terimleri ile Engle (2002) tarafından yapılan çalışmada gösterildiği şekliyle koşullu korelasyon modeli tahmin edilir. Tahmin edilen modeller (1) numaralı eşitliklerde ifade edilmiştir. 


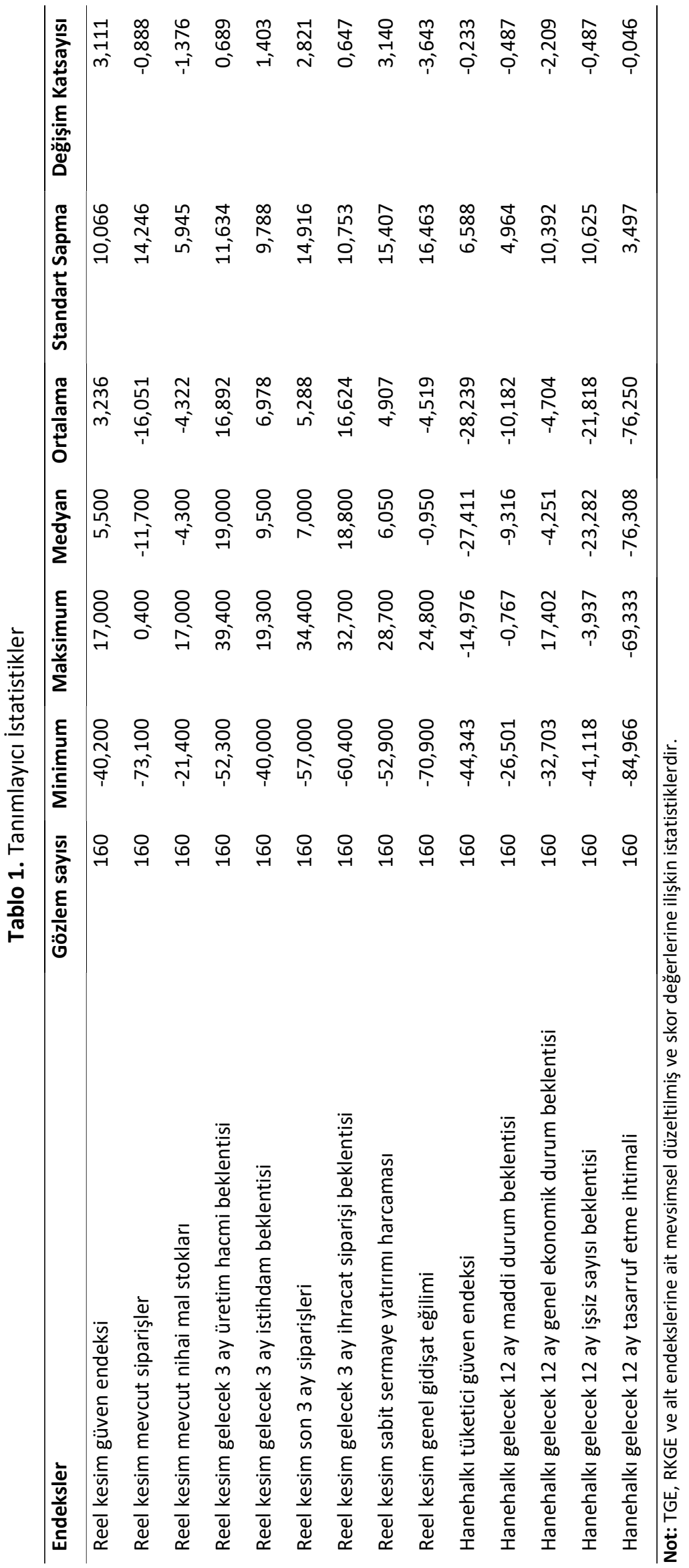




$$
\begin{aligned}
y_{t}=\mu+\epsilon_{t} & \text { (GARCH Ortalama Modeli) } \\
\epsilon_{t}=H_{t}^{1 / 2} u_{t} & \text { (GARCH Varyans Modeli) } \\
H_{t}=D_{t} R_{t} D_{t} & \text { (DCC Modeli) } \\
R_{t}=\operatorname{diag}\left(q_{1,1, t}^{-1 / 2}, \ldots, q_{1,1, t}^{-1 / 2}\right) Q_{t} \operatorname{diag}\left(q_{1,1, t}^{-1 / 2}, \ldots, q_{1,1, t}^{-1 / 2}\right) & \text { (DCC Ayrıştırma) } \\
Q_{t}=(1-\alpha-\beta) \bar{Q}+\alpha u_{t-1} u_{t-1}^{\prime}+\beta Q_{t-1} & \text { (Kovaryans tahmini) }
\end{aligned}
$$

$t=2007: 01, \ldots, 2020: 04$ aralığında 160 gözlem noktasını kapsamak üzere; $y_{t}, y_{t}=\left(y_{1, t}, \ldots, y_{14, t}\right)^{\prime}$ TGE ve RKGE alt endekslerini içeren $(14 \times t)$ uzunluğunda vektörü, $E\left(y_{t}\right)^{\prime}$ nin sıfırdan farklı olması ihtimaline karşı $\mu=\left(\mu_{1}, \ldots, \mu_{14}\right),(14 \times 1)$ uzunluğunda sabit terim vektörünü ve son olarak $\epsilon_{t}$ ise $\epsilon_{t}=\left(\epsilon_{1, t}, \ldots, \epsilon_{14, t}\right)^{\prime}$ $(14 \times t)$ boyutlu, $E\left(u_{t}\right)=0$ ve $s \neq t$ için $E\left(u_{t}, u_{s}^{\prime}\right)=0$ özelliklerine sahip olan beyaz gürültü sürecini temsil etmektedir.

$E\left(u_{t}, u_{t}^{\prime}\right)=H_{t}$ varyansa sahip hata terimleri $H_{t}=\left(h_{i, j, t}\right)$ ise $i, j=1, \ldots, 14$ olmak üzere $t^{\prime}$ ye bağlı koşullu kovaryans matrisine sahiptir ve $I$ ise $(14 \times 14)$ birim matrisi temsil etmektedir. $D_{t}=$ $\operatorname{diag}\left(H_{1,1, t}^{1 / 2}, \ldots, H_{14,14, t}^{1 / 2}\right)^{\prime}$, koşullu varyansın karekökünün köşegen matrisini ifade etmektedir ve içindeki her bir $h_{i, j, t}$ için GARCH süreci tanımlanmaktadır.

$R_{t}$ ise $(14 \times 14)$ boyutlarında ve $t^{\prime}$ ye bağı ılarak değişen koşullu korelasyonları, diğer bir ifadeyle TGE ve RKGE alt endeksleri arasındaki ilişkinin ölçüsünü göstermektedir. $Q_{t}=\left(q_{i, j, t}\right), t^{\prime}$ ye bağlı olarak değişen koşullu kovaryansları ifade etmekte ve $u_{t}=\left(u_{1, t}, \ldots, u_{14, t}\right)^{\prime}$ standartlaştırılmış hata terimleri vektörünü, $\bar{Q}$ ise $u_{t}$ 'nin koşulsuz kovaryans matrisini, $\alpha$ ve $\beta$ ise $\alpha+\beta<1$ koşulunu sağlayan pozitif sayıları temsil etmektedir. $\alpha$ tahmini çok değişkenli sistem içindeki ortalama statik koşullu korelasyon tahminini vermektedir.

Antonakakis (2012) tarafından yapılan çalışmada önerildiği gibi, $u_{t}$ 'nin normal dağıldığını ifade eden boş hipotezi reddedildiği için bu çalışmada DCC modeli çok değişkenli $t$ - dağılımı altında en yüksek olabilirlik benzeri (QML) tahmincisi ile tahmin edilmiştir.

Bu çalışmada, istatistiksel olarak anlamlı bulunan TGE ve RKGE alt endeksleri arasındaki zamana bağlı değişen korelasyon katsayıları $\left(R_{t}\right)$ panel veri şeklinde yeniden düzenlenerek $(i=5, t=160, n=800)$, 2007:01-2020:04 döneminde USD/TL kurunun ve COVID-19 salgını $R_{t}{ }^{\prime}$ ler üzerindeki etkileri ölçülmeye çalışılmıştır. Tahmin edilen panel model (2) numaralı eşitlikte ifade edilmiştir.

$$
d c_{i, j, t}=v_{i, j}+\lambda_{1, j} \Delta U S D_{t}+\lambda_{2, j} D_{2020: 04}+\lambda_{3, j} D_{2008: 03}+\varepsilon_{i, j, t}
$$

$d c_{i, j, t} ; R_{t}^{\prime}$ lerin $[-1,1]$ aralığının dışına çıkarılması için $\log \left(\left(1+R_{i, j, t}\right) /\left(1-R_{i, j, t}\right)\right)$ dönüşümü uygulamış halidir. Bu dönüşüm katsayı tahminlerini etkilememektedir. $v_{i, j}$ yatay-kesitler için tanımlanmış sabit terimleri; $\triangle U S D_{t}$ aylık USD/TL getirisini ve $\lambda_{1}$ onun katsayısını; $D_{2020: 04}$ COVID-19 salgının etkisini ölçmek için tasarlanmış 2020:04 için 1, diğer dönemler için 0 olan kukla değişkeni ve $\lambda_{2}$ onun katsayısını; $D_{\text {2008:03 }}$ hata terimlerindeki aykırı değerin model varyansını arttırmasını önlemek için tasarlanmış 2008:03 için 1, diğer dönemler için 0 olan kukla değişkeni ve $\lambda_{3}$ onun katsayısını; $\varepsilon_{i, j, t}$ ise $\varepsilon_{i, j, t} \sim$ n.i.i.d olarak dağılan hata terimini temsil etmektedir. (2) numaralı eşitlik için aylık USD/TL getirisinin yanında aylık sanayi üretim endeksi büyüme oranı, aylık enflasyon ve aylık işsizlik oranı değişkenleri $d c_{i, j, t}$ 'yi açıklamak üzere kullanılmış ancak model tahminlerini bozucu etki yaptığından modele dahil edilmemiştir.

(2) numaralı eşitlik üzerine Hausman (1978) tarafından önerilen spesifikasyon testi yapılarak, Amemiya ve MaCurdy (1986) tarafından önerilen araç değişkenler yöntemi ve Hausman ve Taylor (1981) tarafından önerilen tesadüfi etkiler tahmincisiyle tahmin edilmiştir. Standart hatalar ise Cameron, Gelbach ve Miller (2011) tarafından önerilen kümelenmiş bootstrap yaklaşımına göre \%95 güven düzeyinde 1000 tekrarlı olarak hesaplanmıştır. 


\section{Bulgular}

TGE ve RKGE alt endeksleri arasındaki ilişkinin ölçüldüğü (1) numaralı GARCH-DCC modelinin tahmin sonuçları Tablo 2'de özetlenmiştir ${ }^{1}$. Hosking (1980) tarafından yapılan çalışmada açıklanan ve modelin hata terimlerinde otokorelasyon olmadığını ifade eden boş hipotezi test eden $H_{10}$ testi ile değişen varyans olmadığı boş hipotezini test eden $H_{10}^{2}$ testlerinde, boş hipotezler $\% 5$ anlamlılık düzeyinde reddedilemediği için modelin başarılı tahmin edildiği söylenebilir. Bununla birlikte, Tablo 2'de $\alpha+\beta<1$ koşulunun sağlandığı ve her iki katsayının da istatistiksel olarak \%5 düzeyinde anlamlı olduğu görülmektedir. Model tahmini sonucunda, TGE ve RKGE alt kalemleri arasında istatistiksel olarak anlamlı bir ilişki olduğu iddia edilebilir.

Tablo 2. 2007:01-2020:04 için DCC Modeli Tahmin Sonuçları

\begin{tabular}{|c|c|c|c|}
\hline Katsayı & Tahmini & Std, Hata & $t$-istatistik \\
\hline$\alpha$ & $0,063 * * *$ & 0,023 & 2,719 \\
\hline$\beta$ & $0,480 * *$ & 0,204 & 2,353 \\
\hline Akaike & 69,163 & & \\
\hline Bayes & 72,315 & & \\
\hline Shibata & 68,228 & & \\
\hline Hannan-Quinn & 70,443 & & \\
\hline$H_{10}$ & $2.357,995$ & & \\
\hline$H_{10}^{2}$ & $2.130,356$ & & \\
\hline
\end{tabular}

Not: *** \%1, ** \%5 seviyesinde anlamlı olduğunu gösterir. $H_{10}$ ve $H_{10}^{2}$, Hosking (1980) tarafından yapılan çalışmadaki şekliyle 10 gecikmeye kadar hesaplanmış çok değişkenli Portmanteau test istatistikleridir.

(1) numaralı model aracılığıyla tahmin edilen TGE ve RKGE alt endeksleri arasındaki dinamik koşullu korelasyonların ortalamaları ve t-istatistik değerleri Tablo 3'de verilmiştir. Tabloya göre, TGE ve RKGE alt endeksleri arasındaki [ $(5 \times 9)]$ tekil 45 adet dinamik geçişkenlik katsayısından 5 tanesi istatistiksel olarak \%5 seviyesinde anlamlı bulunmuştur. İstatistiksel olarak anlamlı korelasyon katsayısına sahip olan TGE ve RGKE alt endeksleri arasındaki ilişkiler Şekil 1'de özetlenmeye çalışılımıştır.

Şekil 1'de TGE'nin alt endeksleri arasından genel ekonomik durum beklentisi, işsiz sayısı beklentisi ve tasarruf etme ihtimali endeksleri ile RKGE'nin temel, genel gidişat ve son üç aylık siparişler endeksleri arasında istatistiksel olarak \%5 düzeyinde anlamlı ilişkiler olduğu görülmektedir. Daha açık bir ifadeyle,

- Reel kesim gelecek 3 ay istihdam beklentisi ile Hanehalkı gelecek 12 ay tasarruf etme ihtimali arasında $(\hat{\rho}=0,2)$,

- Hanehalkı gelecek 12 ay genel ekonomik durum beklentisi ile Reel kesim genel gidişat eğilimi arasında $(\hat{\rho}=0,168)$,

- Reel kesim genel gidişat eğilimi ile Hanehalkı gelecek 12 ay işsiz sayısı beklentisi arasında $(\hat{\rho}=$ $0,193)$,

- Hanehalkı gelecek 12 ay işsiz sayısı beklentisi ile Reel kesim güveni arasında $(\hat{\rho}=0,173)$,

- Hanehalkı gelecek 12 ay işsiz sayısı beklentisi ile Reel kesim son 3 ay siparişleri arasında ( $\hat{\rho}=$ $0,203) \% 5$ düzeyinde istatistiksel olarak anlamlı ilişkiler olduğu görülmüştür.

Grafik 2'de istatistiksel olarak anlamlı olarak tespit edilen TGE ve RGKE alt endeksleri arasındaki dinamik koşullu korelasyon katsayılarının zaman içindeki eğilimleri verilmiştir. TGE ve RGKE alt endeksleri arasındaki ilişkinin zaman içindeki değişimine bakıldığında genel olarak sabit bir ortalama etrafında oynak bir seyir 
gösterdiği gözlemlenmiştir. Özellikle, 2010 yılı öncesinde ve 2016 yılı sonrasında ilişkinin değişkenlik göstermektedir.

Tablo 3. 2005:02-2020:04 için RKGE ve TGE Alt Endeksleri Arasındaki DCC Ortalamaları

\begin{tabular}{lcccccc} 
& & HG12GEDB & HG12ISSIZ & HG12MDB & HG12TSRRF & TGE \\
\hline RKG3IHRSIP & $\hat{\rho}$ & $-0,013$ & $-0,018$ & $-0,003$ & $-0,034$ & $-0,028$ \\
& & {$[-0,16]$} & {$[-0,22]$} & {$[-0,04]$} & {$[-0,36]$} & {$[-0,73]$} \\
\hline RKG3IST & $\hat{\rho}$ & 0,095 & 0,122 & 0,129 & $0,200^{* *}$ & 0,108 \\
& & {$[1,19]$} & {$[1,54]$} & {$[1,63]$} & {$[2,56]$} & {$[1,36]$} \\
\hline RKG3UHCM & $\hat{\rho}$ & 0,076 & 0,059 & 0,097 & 0,030 & 0,049 \\
& & {$[0,95]$} & {$[0,74]$} & {$[1,22]$} & {$[0,38]$} & {$[0,62]$} \\
\hline RKGE & $\hat{\rho}$ & 0,131 & $0,173^{* *}$ & 0,063 & 0,073 & 0,095 \\
& & {$[1,66]$} & {$[2,21]$} & {$[0,80]$} & {$[0,92]$} & {$[1,20]$} \\
\hline RKGG & $\hat{\rho}$ & $0,168^{* *}$ & $0,193^{* *}$ & 0,084 & 0,081 & 0,141 \\
& & {$[2,14]$} & {$[2,48]$} & {$[1,06]$} & {$[1,03]$} & {$[1,79]$} \\
\hline RKMSIP & $\hat{\rho}$ & 0,110 & 0,114 & $-0,019$ & 0,007 & 0,048 \\
& & {$[1,39]$} & {$[1,44]$} & {$[-0,24]$} & {$[0,09]$} & {$[0,60]$} \\
\hline RKMSTOK & $\hat{\rho}$ & 0,034 & 0,023 & 0,006 & 0,042 & 0,021 \\
& & {$[0,43]$} & {$[0,30]$} & {$[0,07]$} & {$[0,53]$} & {$[0,27]$} \\
\hline RKS3SIP & $\hat{\rho}$ & 0,141 & $0,203^{* *}$ & 0,078 & 0,122 & 0,126 \\
& & {$[1,79]$} & {$[2,61]$} & {$[0,99]$} & {$[1,54]$} & {$[1,60]$} \\
\hline RKYTHRCM & $\hat{\rho}$ & 0,087 & 0,067 & 0,027 & 0,003 & 0,036 \\
& & {$[1,09]$} & {$[0,85]$} & {$[0,34]$} & {$[0,04]$} & {$[0,46]$} \\
\hline
\end{tabular}

Not: $\hat{\rho}$ : DCC katsayılarının ortalama tahmini, köşeli parantez içindekiler t-istatistiği değerini, ** \%5 seviyesinde anlamlı olduğunu gösterir.

Tablo 4'te (2) numaralı model için Hausman test sonucu verilmiştir. Tesadüfi etkiler tahmincisinin önerildiği boş hipotezin reddedilemediği görülmektedir. Dolayısıyla, tesadüfi etkiler tahmincisi kullanılarak (2) numaralı model tahmin edilmiştir. Tablo 5'te (2) numaralı modelin tahmin sonuçlarına yer verilmiştir.

Şekil 1. TGE ve RKGE Alt Endeksleri Arasındaki İlişki

$\begin{gathered}\text { Reel kesim } \\ \text { gelecek } 3 \text { ay } \\ \text { istihdam } \\ \text { beklentisi }\end{gathered}$
$\begin{gathered}\text { Hanehalkı } \\ \text { gelecek } 12 \text { ay } \\ \text { tasarruf etme } \\ \text { ihtimali }\end{gathered}$
Reel kesim güven endeksi


Şekil 2. TGE ve RKGE Alt Endeksleri Arasındaki DCC Katsayıları

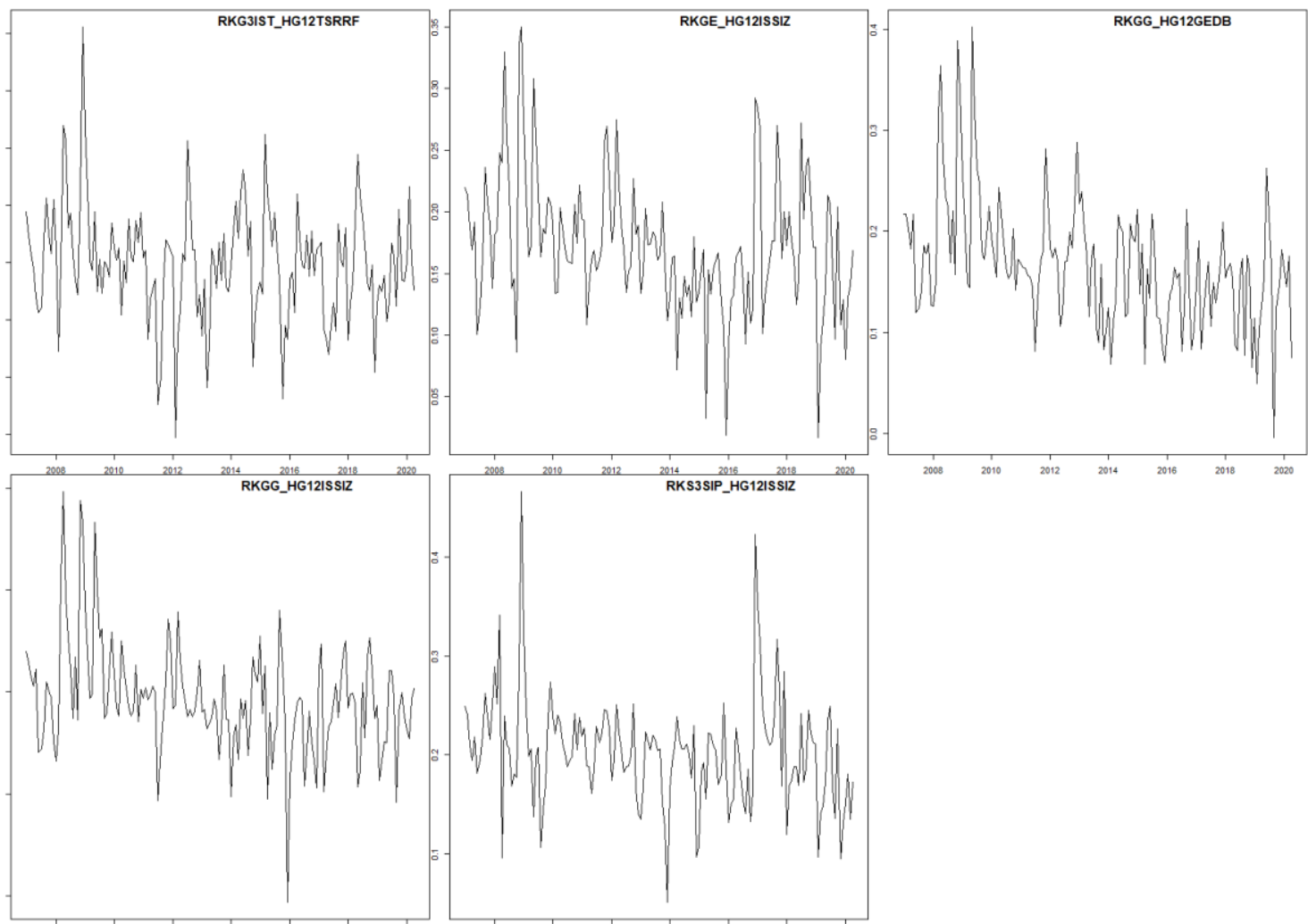

Tablo 4. Hausman Test Sonuçları

\begin{tabular}{ccc}
\hline Test istatistiği & Serbestlik Derecesi & Alternatif Hipotez \\
\hline 0,00034 & 3 & Sabit etkiler \\
\hline
\end{tabular}

Tablo 5. Panel Model Tahmin Sonuçları

\begin{tabular}{|c|c|c|c|}
\hline Değişken & Tahmin & Std. Hata & z-istatistiği \\
\hline$\hat{v}$ & $0,378 * * *$ & 0,015 & 25,023 \\
\hline$\Delta U S D_{t}$ & $-0,282 * * *$ & 0,120 & $-2,353$ \\
\hline$D_{2008: 03}$ & $0,289 * * *$ & 0,066 & 4,383 \\
\hline$D_{2020: 04}$ & $-0,034$ & 0,034 & $-0,996$ \\
\hline \multicolumn{4}{|c|}{$\begin{array}{l}\text { Not: *** \%1 seviyesinde anlamlı olduğunu gösterir. } \\
\text { İstatistiksel güvenilirlikler, Cameron, Gelbach ve Miller } \\
\text { (2011) tarafından önerilen kümelenmiş bootstrap } \\
\text { yaklaşımına göre \%95 güven düzeyinde } 1000 \text { tekrarlı } \\
\text { olarak hesaplanmıştır. }\end{array}$} \\
\hline
\end{tabular}

USD/TL kurunun aylık getirilerinin dinamik koşullu korelasyonlar üzerinde negatif ve istatistiksel olarak anlamlı etkisinin olduğu görülmektedir. Dolayısıyla, USD/TL kurunun aylık getirileri arttıkça (azaldıkça) TGE ve RKGE alt endeksleri arasındaki ilişki azalmaktadır (artmaktadır). Bu durum, USD/TL kuru artışının TGE ile RKGE'yi birbirinden ayrıştırdığını ve dolayısıyla TGE ile RKGE üzerinde farklı etkiler yarattı̆̆ını ima etmektedir. Diğer taraftan, COVID-19 salgınının 2020 yılının 4. ayındaki etkisini temsil eden katsayının istatistiksel olarak anlamsız olduğu gözlemlenmiş ve TGE ile RKGE arasındaki ilişkiyi etkilemediği anlaşılmıştır. 


\section{Sonuç}

Türkiye'de hanehalkı ve reel sektör beklentilerini ölçmek üzere Tüketici Güven Endeksi ve Reel Kesim Güven Endeksi göstergeleri yayımlanmaktadır. Literatürde bu endekslerin diğer ekonomik göstergeler ile aralarındaki ilişkiler sıkça araştırılmasına rağmen, birbirleri arasındaki ilişkiyi araştıran çalışma sayısı oldukça azdır.

Literatürden farklı olarak, bu çalışmada TGE ve RKGE alt endeksleri arasındaki ilişki Ocak 2007 ile Nisan 2020 dönemi için DCC-GARCH modeli kullanılarak analiz edilmiştir. Alt endeksler arasında tahmin edilen istatistiksel olarak anlamlı dinamik koşullu korelasyon katsayıları üzerinde USD/TL ve COVID-19 salgının etkilerini ölçmek üzere panel veri analizi uygulanmıştır.

DCC-GARCH modeli tahmininden elde edilen bulgulara göre, TGE ve RKGE alt endeksleri arasında istatistiksel olarak anlamlı ancak zayıf bir ilişkinin var olduğu iddia edilebilir. TGE ve dört alt endeksi ile RKGE ve 8 alt endeksi arasında olası 40 adet ilişkiden $5^{\prime} i$ istatistiksel olarak anlamlı bulunmuştur. Hanehalkının gelecek 12 ayda tasarruf etme ihtimali, ekonominin genel durumu ve işsiz sayısı beklentileri ile reel kesimin ekonominin genel gidişatı ve sipariş sayısına ilişkin beklentileri arasındaki ilişkiler istatistiksel olarak anlamlı bulunmuştur. Bununla birlikte, zamana bağlı değişen korelasyon katsayılarının özellikle 2010 yılı öncesi ve 2016 yılı sonrasında oldukça değişken olduğu gözlemlenmiştir.

Panel veri analizi sonucunda, TGE ve RKGE alt endeksleri arasındaki anlamlı dinamik korelasyon katsayılarının USD/TL kurunun aylık getirilerinden negatif etkilendiği tespit edilmiştir. Bu bulgu, USD/TL kurundaki artışların (azalışların) TGE ve RKGE arasındaki ilişkiyi azalttığına (arttırdığına) işarettir. Dolayısıyla, USD/TL kuru arttıkça hanehalkı ve reel sektör beklentileri ayrışmakta, tersi durumda ise beraber hareketleri güçlenmektedir. Diğer taraftan, COVID-19 salgınının TGE ve RKGE arasındaki ilişki üzerinde istatistiksel olarak anlamlı bir etki yaratmadığı gözlemlenmiştir. Bu bulgudan hareketle COVID-19 salgınının 2020 yılı Nisan ayı itibarıyla hanehalkı ve reel sektör beklentileri arasındaki ilişkiyi ayrıştırıcı ya da güçlendirici bir etki yaratmadığı sonucu çıkarılabilir. Diğer taraftan, bu bulgu COVID-19 salgınının 2020 yılı boyunca söz konusu ilişkiyi etkilemeyeceğini göstermez.

Sonuç olarak, USD/TL kurundaki istikrarın hanehalkı ve reel kesimin beklentileri arasındaki uyumu arttıracağı değerlendirilmektedir. Ayrıca, hanehalkı ve reel kesimin beklentilerindeki iyileşmenin ekonomik göstergeler üzerinde olumlu yansımasının birlikte hissedileceği düşünülmektedir. Diğer taraftan, ekonomik göstergeler üzerindeki etkilerinin henüz sınırlı bir şekilde ölçülebildiği COVID-19 salgını sonrasında hanehalkı ve reel kesim beklentilerindeki toparlanmanın beraber gerçekleşeceği değerlendirilmektedir.

\section{Beyan ve Açıklamalar (Disclosure Statements)}

1. Bu çalışmanın yazarı, araştırma ve yayın etiği ilkelerine uyduğunu kabul etmektedir (The author of this article confirms that her work complies with the principles of research and publication ethics).

2. Yazar tarafından herhangi bir çıkar çatışması beyan edilmemiştir (No potential conflict of interest was reported by the author).

3. Bu çalışma, intihal tarama programı kullanılarak intihal taramasından geçirilmiştir (This article was screened for potential plagiarism using a plagiarism screening program).

\section{Son Notlar}

1. Bulguları kısa tutmak amacıyla ilk aşamadaki GARCH tahmin sonuçlarına burada yer verilmemiştir. Talep edilmesi durumunda detaylı sonuçlar paylaşılabilir. 


\section{Kaynaklar}

Afshar, T., Arabian, G., \& Zomorrodian, R. (2007). Stock return, consumer confidence, purchasing managers index and economic fluctuations. Journal of Business \& Economics Research (JBER), 5(8), 97-106.

Albayrak, Ş. G. (2018). Türkiye'de reel kesim güven endeksi ve imalat sanayi kapasite kullanım oranı arasındaki ilişki üzerine ampirik bir uygulama (2007-2017). Akademi Sosyal Bilimler Dergisi, 5(15), 18-27.

Amemiya, T., \& MaCurdy, T. E. (1986). Instrumental-variable estimation of an error-components model. Econometrica, 54(4), 869-880.

Antonakakis, N. (2012). Business cycle synchronization during US recessions since the beginning of the 1870s. Economics Letters, 117(2), 467-472.

Arısoy, i.., \& Cengiz, A. (2014). Türkiye'de tüketim harcamaları, krediler ve tüketici güveni arasındaki ilişkilerin analizi. Business and Economics Research Journal, 5(2), 33-45.

Ay, B. (2019). İmalat sanayi kapasite kullanım oranı ve reel kesim güven endeksi arasındaki ilişki: Türkiye için ampirik bir çalışma. The Journal of Social Science, 3(5), 376-389.

Ayuningtyas, R., \& Koesrindartoto, D. P. (2014). The relationship between business confidence, consumer confidence and indexes return: Empirical evidence in Indonesia stock exchange. In Proceedings of International Conference on Trends in Economics, Humanities and Management, 21-25.

Başel F., \& Yardımcıoğlu, F. (2016). Tüketici güven endeksi ile makro değişkenler arasındaki ilişki. Uluslararası Politik, Ekonomik ve Sosyal Araştırmalar Kongresi (ICPESS), 475-487.

Bremmer, D. S., \& Christ, K. P. (2003). The relationship between consumer sentiment and stock prices. In Proceedings of Annual Conference of the Western Economic Association International, Denver, Colorado, USA.

Cameron, A. C., Gelbach, J. B., \& Miller, D. L. (2011). Robust inference with multiway clustering. Journal of Business \& Economic Statistics, 29(2), 238-249.

Canöz, ì. (2018). Borsa İstanbul 100 endeksi ile tüketici güven endeksleri arasındaki nedensellik ilişkisi: Türkiye örneği. Fiscaoeconomia, 2(1), 136-153.

Chen, S. S. (2011). Lack of consumer confidence and stock returns. Journal of Empirical Finance, 18(2), 225-36.

Demirgil, B. (2019). Ekonomik büyümede güven faktörünün etkisi: Türkiye örneği. Avrasya Sosyal ve Ekonomi Araştırmaları Dergisi, 6(3), 155-163.

Durgun, A. (2019). Türkiye'de tüketici ve reel kesim güven endeksi ile seçilmiş makro değişkenler arasındaki ilişkiler: 2010-2018. Yönetim ve Ekonomi Araştırmaları Dergisi, 17(1), 314-332.

Engle, R. (2002). Dynamic conditional correlation: A simple class of multivariate generalized Autoregressive conditional heteroskedasticity models. Journal of Business \& Economic Statistics, 20(3), 339-350.

Fisher, K. L., \& Statman, M. (2003). Consumer confidence and stock returns. The Journal of Portfolio Management, 30(1), 115-127.

Gülcan, N. H., \& Akkuş, T. (2019). Türkiye'de farklı kesimler için oluşturulan güven endeksleri arasındaki uyum ve etkileşimin incelenmesi. Muhasebe ve Finans incelemeleri Dergisi, 2(1), 11-19.

Hausman, J. A. (1978). Specification tests in econometrics. Econometrica, 46(6), 1251-1271.

Hausman, J. A., \& Taylor, W. E. (1981). Panel data and unobservable individual effects. Econometrica, 49(6), 1377-1398.

Hosking, J. R. M. (1980). The multivariate portmanteau statistic. Journal of the American Statistical Association, 75(371), 602-608.

Hsu, C. C., Lin, H. Y., \& Wu, J. Y. (2011). Consumer confidence and stock markets: The panel causality evidence. International Journal of Economics and Finance, 3(6),91-98.

Islam, T. U., \& Mumtaz, M. N. (2016). Consumer confidence index and economic growth: An empirical analysis of EU countries. EuroEconomica, 35(2), 17-22.

Kandır, S. Y. (2006). Tüketici güveni ve hisse senedi getirileri ilişkisi: iMKB mali sektör şirketleri üzerinde bir uygulama. Çukurova Üniversitesi Sosyal Bilimler Enstitüsü Dergisi, 15(2), 217-230.

Korkmaz, T., \& Çevik, E. İ. (2009). Reel kesim güven endeksi ile IMKB 100 endeksi arasındaki dinamik nedensellik ilişkisi. istanbul University Journal of the School of Business Administration, 38(1), 24-37.

Loría, E., \& Brito, L. (2004). Is the consumer confidence index a sound predictor of the private demand in the United States? Estudios de Economía Aplicada, 22(3), 795-809. 
Sum, V. (2014). Effects of business and consumer confidence on stock market returns: Cross-sectional evidence. Economics, Management and Financial Markets, 9(1), 21-25.

Usul, H., Küçüksille, E., \& Karaoğlan, S. (2017). Güven endekslerindeki değişimlerin hisse senedi piyasalarına etkileri: Borsa İstanbul örneği. Süleyman Demirel University Journal of Faculty of Economics \& Administrative Sciences, 22(3), 685-695.

Yalçın, E. C., Tıraşoğlu, M., \& Çevik, E. (2017). Bölgesel bazlı konut fiyat endeksi ile ekonomik güven endeksi arasındaki ilişkinin ekonometrik analizi: Türkiye örneği. Girişimcilik ve Kalkınma Dergisi, 12(2), 123-137.

Yamak, R., Yamak, N., \& Erkan, E. (2019). Tüketim fonksiyonu ve tüketici güven endeksi. Kafkas University Faculty of Economics and Administrative Sciences Journal, 10(19), 511-32. 